\title{
Knowledge and Perception of Malaria Rapid Diagnostic Test among Medical Doctors in a South Eastern Nigeria Tertiary Hospital
}

\author{
Edmund 0. Ndibuagu ${ }^{*}$, Ogechukwu F. Amadi ${ }^{2}$, Ejiofor T. Ugwu ${ }^{3}$ \\ ${ }^{1}$ Department of Community Medicine and Primary Health Care, Enugu State University College of Medicine, Enugu, Nigeria \\ ${ }^{2}$ Department of Paediatrics, Enugu State University College of Medicine, Enugu, Nigeria \\ ${ }^{3}$ Department of Internal Medicine, Enugu State University College of Medicine, Enugu, Nigeria \\ Email: ${ }^{*}$ edmund.ndibuagu.esut.edu.ng
}

How to cite this paper: Ndibuagu, E.O., Amadi, O.F. and Ugwu, E.T. (2017) Knowledge and Perception of Malaria Rapid Diagnostic Test among Medical Doctors in a South Eastern Nigeria Tertiary Hospital. Journal of Biosciences and Medicines, 5, 1-16. https://doi.org/10.4236/jbm.2017.510001

Received: August 30, 2017

Accepted: October 20, 2017

Published: October 23, 2017

Copyright $\odot 2017$ by authors and Scientific Research Publishing Inc. This work is licensed under the Creative Commons Attribution International License (CC BY 4.0).

http://creativecommons.org/licenses/by/4.0/

\begin{abstract}
Malaria commonly causes fever in tropical Africa. In 2010, World Health Organization recommended parasitological diagnosis of malaria before treatment. Rapid Diagnostic Test (RDT) aims at making malaria diagnosis more accessible. The objective of this study was to assess knowledge, and perception of malaria rapid diagnostic test (mRDT), among doctors in a tertiary health facility. A descriptive, cross sectional study, conducted in October 2016, in a state University Teaching hospital, Enugu state, Nigeria. 86 doctors in the General Outpatient, Internal Medicine, and Paediatrics departments participated. $90.7 \%$ of respondents knew parasitological examination of blood is the certain method of making malaria diagnosis, $89.5 \%$ knew microscopy and RDT are methods for parasitological diagnosis, $91.9 \%$ knew mRDT is quick blood test for malaria, $54.7 \%$ knew mRDT is usually specific for one or more species of malaria, $46.5 \%$ knew mRDT detects circulating malaria parasite antigen, $29.1 \%$ knew mRDT is read 15 to 20 minutes after the test, $70.9 \%$ knew $\mathrm{mRDT}$ is not superior to microscopy, $79.1 \%$ knew mRDT is not $100 \%$ specific, $80.2 \%$ knew mRDT ought not be done always by Laboratory Scientists, and $66.3 \%$ knew more than one type of mRDT kit is available. On perception, $64.0 \%$ thought it was important to confirm diagnosis before commencing treatment, $90.7 \%$ perceived $\mathrm{mRDT}$ as being very useful, $96.5 \%$ did not perceive $\mathrm{mRDT}$ as endangering patients, $70.9 \%$ opinioned that presumptive diagnosis of malaria is not a better way of making diagnosis, $76.7 \%$ did not believe malaria diagnosis is always clear on listening to the patient, $90.7 \%$ did not perceive $\mathrm{mRDT}$ as being hazardous, $83.7 \%$ believe using $\mathrm{mRDT}$ can reduce the quantity of anti-malaria drugs consumed, and $94.2 \%$ opinioned that mRDT should be encouraged and promoted. Training and re-training of health workers shall greatly enhance mRDT use in implementing the WHO
\end{abstract}


T3 Initiative, and ultimately eliminating malaria.

\section{Keywords}

Malaria, Test, Doctors, Knowledge, Perception

\section{Introduction}

Malaria is a disease caused by parasites of the genus Plasmodium and usually transmitted by infected female Anopheline mosquito [1]. The four common species of Plasmodium which infect man are Plasmodium falciparum, Plasmodium vivax, Plasmodium ovale, and Plasmodium malariae. Rarely, malaria infection in man is caused by the monkey malaria parasite Plasmodium knowlesi which has been reported from the forest region of South-East Asia [2]. This disease is the commonest cause of fever in tropical Africa, and accounts for the highest number of persons who visit health facility for treatment in that part of the world [3]. In December 2016, World Health Organization (WHO) estimated that about 212 million cases of malaria occurred globally in 2015, resulting in about 429,000 deaths. Most of these cases and death, which are as high as $90 \%$ and $92 \%$ respectively occurred in Sub-Sahara African [4]. The disease still poses significant public health problem, with about 3.2 billion people being at risk globally [5]. It is estimated in Nigeria that about $97 \%$ of the population is at risk of malaria infection [6].

Estimates revealed that 39\% of global malaria deaths, and 34\% of cases in 2013 occurred in Nigeria and democratic Republic of Congo [7]. As at 2006 in Nigeria, $60 \%$ of outpatient attendance, $30 \%$ inpatient admissions, and $11 \%$ of maternal deaths were attributable to malaria disease [8]. Estimates in 2011 also showed that in Nigeria, more than 140 million people are at risk of malaria infection every year, and $50 \%$ of adult population have at least one episode of malaria yearly, while children under 5 years of age experience about 2 - 4 episodes of malaria infection every year. That same year, economic loss in Nigeria that was attributable to malaria infection was put at 132 billion Naira [9].

In the past, malaria diagnosis was mostly based on clinical presentation, but in 2010, the World Health Organization (WHO) recommended that parasitological diagnosis of malaria through microscopy or Rapid Diagnostic Test (RDT) should be confirmed before commencement of treatment [10]. This is to minimize malaria over diagnosis and misdiagnosis observed in malaria endemic countries in Africa and Asia [11]. Microscopy is the gold standard for malaria diagnosis, but it has some drawbacks such as being dependent on trained and skilled personnel, availability of power supply, and availability of consumables required for microscopy [12]. It is only when a parasitological diagnosis of malaria is not accessible, could treatment of malaria be commenced, based only on clinical diagnosis [13]. Despite its documented demerits such as irrational use of 
anti-malaria drugs, and lost opportunities to make correct diagnosis of certain fever conditions; presumptive treatment of malaria is still rampant in Sub-Saharan Africa [14]. More than $80 \%$ of malaria treatment in about half of endemic African countries is done without laboratory confirmation of the diagnosis [15]. In Enugu state Nigeria, which is our study area, it was found in the year 2009 that over $50 \%$ of malaria diagnosis was made presumptively [16]. Rapid Diagnostic Test is aimed at making malaria diagnosis more accessible.

The "T3: Test, Treat, Track" initiative was launched by WHO in April 2012 with the aim of improving access to diagnosis and treatment of malaria, as well as encouraging surveillance of the disease. This initiative set an ambitious target of globally achieving access to malaria diagnostic test in both private and public health facilities by the year 2015. The main tool proposed for actualizing this target was RDT [15].

The World Health Organization's recommended Turn-Around-Time (TAM) for diagnostic result for malaria laboratory test to be available to the health care provider is two hours. This usually is not possible in most health facilities in endemic countries such as Nigeria where microscopy with its attendant shortcomings is still largely used for parasitological diagnosis of malaria. Even where the patients are sent for parasitological diagnosis, doctors usually prescribed anti-malaria drugs without waiting for the result. The shortcomings associated with malaria microscopy include insufficient/no dedicated microscope, overworked/insufficient Laboratory Scientists, and challenges with power supply [10]. In line with the WHO recommendation that diagnosis of malaria should be confirmed before suspected cases are given drugs, Nigeria in 2011 included this in her National Malaria Treatment Guidelines [17]. The second objective of the Nigeria National Malaria Strategic Plan 2014-2020 is that, "All persons with suspected malaria who seek care are tested with RDT or microscopy by 2020" [6].

The use of malaria RDT in most endemic countries is still low [18], and in many cases where they are used, the anti-malaria prescription behaviour of doctors and other health workers is not influenced by the result [19]. Though some studies in Nigeria have reported efficacy of malaria RDT similar to the results obtained through microscopy, and that RDT in the management of malaria cases is cost effective [16] [20], many health workers still prescribe anti-malaria drugs to patients that tested negative to malaria rapid diagnostic test [21]. Tertiary hospitals are the apex referral hospitals for treatment of communicable diseases including malaria in Nigeria. It is important that medical doctors, especially those working in tertiary health facilities are equipped with adequate knowledge of malaria RDT, have positive perception about RDT, and make use of this malaria diagnostic tool as recommended by WHO, and Federal Ministry of Health. An assessment of the level of knowledge, and perception of malaria rapid diagnostic test among medical doctors working in a tertiary hospital, will reveal the gaps in these areas, thus serving as a guide towards developing appropriate 
strategy aimed at enhancing the use of malaria RDT in the management of fever cases in tertiary health facilities. The main objective of this study is to assess the knowledge, and perception of malaria rapid diagnostic test, among medical doctors working in a tertiary health facility.

\section{Methodology}

This study was conducted in October 2016, in a state University Teaching hospital in Enugu state, Southeast Nigeria. The state has four public tertiary health facilities, among which are two teaching hospitals. One of the teaching hospitals is owned by the federal government, while our study site is Enugu state University Teaching Hospital, owned by the state government. The hospital operates all the clinical departments, but doctors in the Outpatient, Internal Medicine, and Paediatrics departments were deliberately enrolled in the study, since they are charged with the responsibility of managing malaria cases that present in the hospital.

The study was a whole population study, employing descriptive, cross sectional design. Self administered questionnaire was given to all the medical doctors working in the three departments stated above, ranging from House Officers to Consultants. Professors and authors of this paper were excluded from the study. All eligible twenty four doctors working in the General Outpatient department completed and returned their questionnaire, while out of the thirty two eligible doctors in Internal Medicine department, thirty completed and returned. Thirty two eligible doctors in the department of Paediatrics out of thirty five, completed and returned their questionnaire. Thus the overall response is eighty six doctors out of ninety one eligible doctors, giving $94.5 \%$ response rate. The questionnaire was pre-tested at the University of Nigeria Teaching Hospital, a month before the study was conducted. Ethical clearance was obtained from the Research Ethics committee of the Enugu State University College of Medicine. The objective of the research was explained to each respondent, and informed consent obtained from them prior to participation in the study. The respondents were assured that information given by them will be treated with utmost confidentiality.

The information generated was analyzed using Statistical Package for Social Sciences (SPSS) version 20.0, and the findings expressed in frequency and percentage of correct response. Overall knowledge and perception of malaria rapid diagnostic test among doctors in the different departments were determined. Pearson's Chi-Square test of significance was used to check if some of the findings were significant.

\section{Results}

1) Socio-demographic characteristics: A total of 91 copies of the questionnaire were distributed to all the eligible doctors working in the General Outpatient department, Internal Medicine department, and Paediatrics department of Enugu State University Teaching Hospital. Eighty six (86) copies of the ques- 
tionnaire were returned for analysis, giving a response rate of $94.5 \%$. Twenty four (27.9\%) from the General Outpatient department, 30 (34.9\%) from the Internal Medicine department, and 32 (37.2\%) from the Paediatrics department. Forty three (50.0\%) were males, and equal number were females. Most (61.6\%) were between the age ranges 31 - 40 years, while only one respondent was above 60 years of age. Most of the respondents were of the Igbo tribe extraction, while 2 (2.3\%) respondents were of Esan minority tribe, and 1 (1.2\%) was of Idoma minority tribe. Most were married (89.5\%), 6 (7.0\%) single, 2 (2.3\%) divorced/separated, and $1(1.2 \%)$ widowed. All the respondents were Christians by religion.

The Socio-demographic characteristics of the respondents are presented in Table 1 below.

Table 1. Socio-demographic characteristics of respondents.

\begin{tabular}{|c|c|}
\hline Variables & $\mathrm{N}(\%)$ \\
\hline \multicolumn{2}{|l|}{ Departments } \\
\hline General Out-Patient Department & $24(27.9)$ \\
\hline Paediatrics Department & $32(37.2)$ \\
\hline Internal Medicine Department & $30(34.9)$ \\
\hline \multicolumn{2}{|l|}{ Sex } \\
\hline Female & $43(50)$ \\
\hline Male & $43(50)$ \\
\hline \multicolumn{2}{|l|}{ Age at last birthday } \\
\hline $24-30$ years & $16(18.6)$ \\
\hline $31-35$ years & $29(33.7)$ \\
\hline $36-40$ years & $24(27.9)$ \\
\hline 41 - 45 years & $10(11.6)$ \\
\hline $46-50$ years & $2(2.3)$ \\
\hline $51-55$ years & $1(1.2)$ \\
\hline 56 - 60 years & $3(3.5)$ \\
\hline 61 years and above & $1(1.2)$ \\
\hline \multicolumn{2}{|l|}{ Tribe } \\
\hline Igbo & $83(96.5)$ \\
\hline Esan & $2(2.3)$ \\
\hline Idoma & $1(1.2)$ \\
\hline \multicolumn{2}{|l|}{ Marital Status } \\
\hline Married & $77(89.5)$ \\
\hline Single & $6(7.0)$ \\
\hline Divorced/Separated & $2(2.3)$ \\
\hline $\begin{array}{l}\text { Widowed } \\
\text { sytax }\end{array}$ & $1(1.2)$ \\
\hline \multicolumn{2}{|l|}{ Religion } \\
\hline Christianity & $86(100)$ \\
\hline
\end{tabular}


2) Basic knowledge of MALARIA RAPID DIAGNOSTIC TEST: Most of the respondents [78 (90.7\%)] knew that parasitological examination of the blood is the certain method of making a diagnosis of malaria infection. Respondents from the Paediatrics department scored highest (96.9\%) on this while doctors in the Internal Medicine department recorded the least score of $80.0 \%$, and those in the General Outpatient department scored 95.8\%. Microscopy, and Rapid Diagnostic Test (RDT) being the methods used for parasitological diagnosis of malaria was known by [77 $(89.5 \%)]$ of respondents, with Internal Medicine scoring the least (83.3\%); while General Outpatient and Paediatrics departments scored $87.5 \%$ and $96.9 \%$ respectively. Seventy nine doctors (91.9\%) knew that Malaria Rapid diagnostic test (mRDT) is the quick blood test for malaria diagnosis, and doctors in Internal Medicine department again recorded the lowest score of 90.0\%. The highest score of $93.8 \%$ was found in the Paediatrics department, while $91.7 \%$ was found in the General Outpatient department. Only about half of the respondents [47 (54.7\%)] knew that mRDT is usually specific for one or more species of malaria parasite. The poorest score of $30.0 \%$ was reported among doctor in the Internal Medicine department; $66.7 \%$ was found among General Outpatient doctors, while the highest score of $68.8 \%$ was documented among doctors in the Paediatrics department. The difference in knowledge was significant (Pearson's Chi-Square $=0.019)$. Overall poor knowledge $[40(46.5 \%)$ ] was recorded on mRDT being a test that detects circulating malaria parasite antigen in the blood, with only doctors in the General Outpatient department scoring above 54.2\%, while Internal Medicine and Paediatrics department doctors scored $40.0 \%$, and $46.9 \%$ respectively. A very poor overall knowledge score of $29.1 \%$, on mRDT result being read 15 to 20 minutes after the test, was found. General Outpatient scored 29.2\%, Internal Medicine 13.3\%, and Paediatrics $43.8 \%$. Over $70.0 \%$ of the respondents [61 (70.9\%)] knew that mRDT is not superior to microscopy. The highest score of $78.1 \%$ was recorded among doctors in the Paediatrics department, while General Outpatient and Internal Medicine doctors recorded $70.8 \%$ and $63.3 \%$ respectively. Sixty eight $(79.1 \%)$ respondents knew that mRDT is not $100 \%$ specific. Internal Medicine department doctors recorded the highest score of $83.3 \%$, while $75.0 \%$ and $78.1 \%$ were recorded respectively by doctors in the General Outpatient and Paediatrics departments. Most of the respondents [69 (80.2\%)] knew that mRDT ought not to be done always by Laboratory Scientists. Doctors in the Paediatrics department had the highest score of $93.8 \%$, while the least score of $70.0 \%$ was documented among doctors in the Internal Medicine department. General Outpatient doctors recorded $75.0 \%$. The overall knowledge on more than one type of mRDT kit being available was 57 (66.3\%). Doctors in the Paediatrics department recorded the highest knowledge of $84.4 \%$, followed by doctors in the General Outpatient department (62.5\%), and lastly those in the Internal Medicine department (50.0\%).

Basic knowledge on malaria rapid diagnostic test among the medical doctors is presented in Table 2. 
Table 2. Basic knowledge on MALARIA RAPID DIAGNOSTIC TEST among respondents.

\begin{tabular}{|c|c|c|}
\hline Question & Department & Correct Response \\
\hline \multirow{4}{*}{$\begin{array}{l}\text { Parasite-based examination of the blood is } \\
\text { the certain method of confirming malaria } \\
\text { infection }\end{array}$} & General Outpatient & $23(95.8 \%)$ \\
\hline & Internal Medicine & $24(80.0 \%)$ \\
\hline & Paediatrics & $31(96.9 \%)$ \\
\hline & OVERALL & $78(90.7 \%)$ \\
\hline \multirow{4}{*}{$\begin{array}{l}\text { Parasite-based test can be done } \\
\text { through microscopy or rapid diagnostic }\end{array}$} & General Outpatient & $21(87.5 \%)$ \\
\hline & Internal Medicine & $25(83.3 \%)$ \\
\hline & Paediatrics & $31(96.9 \%)$ \\
\hline & OVERALL & $77(89.5 \%)$ \\
\hline \multirow{3}{*}{$\begin{array}{l}\text { MALARIA RAPID DIANOSTIC TEST } \\
\text { is the quick parasite-based test } \\
\text { for malaria diagnosis }\end{array}$} & General Outpatient & $22(91.7 \%)$ \\
\hline & Internal Medicine & $27(90.0 \%)$ \\
\hline & Paediatrics & $30(93.8 \%)$ \\
\hline \multirow{5}{*}{$\begin{array}{l}\text { MALARIA RAPID DIAGNOSTIC TEST is } \\
\text { usually specific for one or more species of } \\
\text { malaria parasite }\end{array}$} & OVERALL & 79 (91.9\%) \\
\hline & General Outpatient & $16(66.7 \%)$ \\
\hline & Internal Medicine & $9(30.0 \%)$ \\
\hline & Paediatrics & $22(68.8 \%)$ \\
\hline & OVERALL & $47(54.7 \%)$ \\
\hline \multirow{4}{*}{$\begin{array}{l}\text { MALARIA RAPID DIAGNOSTIC TEST } \\
\text { detects Circulating malaria parasite antigen } \\
\text { in the blood }\end{array}$} & General Outpatient & $13(54.2 \%)$ \\
\hline & Internal Medicine & $12(40.0 \%)$ \\
\hline & Paediatrics & $15(46.9 \%)$ \\
\hline & OVERALL & $40(46.5 \%)$ \\
\hline \multirow{4}{*}{$\begin{array}{c}\text { MALARIA RAPID DIAGNOSTIC TEST } \\
\text { result should be read } 15 \text { to } 20 \text { minutes } \\
\text { after the test }\end{array}$} & General Outpatient & $7(29.2 \%)$ \\
\hline & Internal Medicine & $4(13.3 \%)$ \\
\hline & Paediatrics & $14(43.8 \%)$ \\
\hline & OVERALL & $25(29.1 \%)$ \\
\hline \multirow{4}{*}{$\begin{array}{l}\text { MALARIA RAPID DIAGNOSTIC TEST is } \\
\text { superior to microscopy }\end{array}$} & General Outpatient & $17(70.8 \%)$ \\
\hline & Internal Medicine & $19(63.3 \%)$ \\
\hline & Paediatrics & $25(78.1 \%)$ \\
\hline & OVERALL & $61(70.9 \%)$ \\
\hline \multirow{4}{*}{$\begin{array}{l}\text { MALARIA RAPID DIAGNOSTIC TEST is } \\
100 \% \text { specific }\end{array}$} & General Outpatient & $18(75.0 \%)$ \\
\hline & Internal Medicine & $25(83.3 \%)$ \\
\hline & Paediatrics & $25(78.1 \%)$ \\
\hline & OVERALL & $68(79.1 \%)$ \\
\hline \multirow{4}{*}{$\begin{array}{l}\text { MALARIA RAPID DIAGNOSTIC TEST } \\
\text { ought to be done always by Laboratory } \\
\text { Scientists }\end{array}$} & General Outpatient & $18(75.0 \%)$ \\
\hline & Internal Medicine & $21(70.0 \%)$ \\
\hline & Paediatrics & $30(93.8 \%)$ \\
\hline & OVERALL & $69(80.2 \%)$ \\
\hline \multirow{4}{*}{$\begin{array}{c}\text { There is only one type of Malaria } \\
\text { Rapid Diagnostic Test Kit }\end{array}$} & General Outpatient & $15(62.5 \%)$ \\
\hline & Internal Medicine & $15(50.0 \%)$ \\
\hline & Paediatrics & $27(84.4 \%)$ \\
\hline & OVERALL & $57(66.3 \%)$ \\
\hline
\end{tabular}

Overall knowledge score for doctors in the General Outpatient department was $70.8 \%$, those in Internal Medicine scored 60.3\%, and those in Paediatrics department scored 78.2\%. 
3) Perception of MALARIA RAPID DIAGNOSTIC TEST: Over 60\% of respondents [55 (64.0\%)] thought that it was important to confirm a diagnosis with a parasitological test of malaria before commencing treatment. The highest score of $70.8 \%$ was recorded among doctors working in the General Outpatient department, $68.8 \%$ recorded in the Paediatrics department, and $53.3 \%$ in the Internal Medicine department. Seventy eight (90.7\%) respondents across board perceived mRDT as being very useful. All the doctors in the outpatient department (100\%) had this perception, and was followed by doctors in the Paediatrics department (93.8\%), and lastly those in the Internal Medicine department (80.0\%). Most of the respondents (96.5\%) do not perceive mRDT as endangering the patient, by delaying initiation of treatment. Again all the doctors in the General Outpatient department (100\%) held this correct perception, while $96.9 \%$ and $93.8 \%$ of those in Internal Medicine and Paediatrics departments respectively had this correct perception. Sixty one (70.9\%) of all respondents are of the opinion that presumptive diagnosis of malaria is not a better way of making a diagnosis of malaria. Doctors in the Outpatient department scored highest on this $(95.8 \%)$, followed by those in the Paediatrics department (68.8\%), and lastly Internal Medicine (53.3\%). Overall, most of the doctors do not believe that malaria diagnosis is always clear on listening to the patient [66 (76.7\%)]. The highest score of $91.7 \%$ was recorded in the General Outpatient department, followed by $73.3 \%$ in the Internal Medicine department, and $68.8 \%$ in the Paediatrics department. Majority of the respondents [78 (90.7\%)] correctly do not perceive mRDT as being hazardous. All the doctors in the General Outpatient department $(100 \%)$ did not report the wrong perception that mRDT is hazardous. Doctors in the Internal Medicine and Paediatrics departments correctly scored $90.0 \%$ and $84.4 \%$ respectively. Seventy two $(83.7 \%)$ of overall participating doctors correctly believe that using mRDT can reduce the quantity of anti-malaria drugs consumed in a community. The highest score was documented in the General Outpatient department (91.7\%), followed by Paediatrics department (87.5\%), then Internal Medicine (73.3\%). Majority of the respondents [81 $(94.2 \%)]$ were of the opinion that Malaria rapid diagnostic test should be encouraged and promoted. All the doctors in the General Outpatient department (100\%) held this view, while $96.9 \%$ and $86.7 \%$ of doctors in the Paediatrics and Internal Medicine departments, respectively had same opinion.

Perception of malaria rapid diagnostic test among the medical doctors is presented in Table 3.

\section{Discussion}

The target population for this study was all the doctors working in the General Outpatient, Internal Medicine, and Paediatrics departments of a state owned Teaching Hospital, excluding Professors, and the three authors. The departments were selected because they manage the bulk of malaria cases that present in the hospital. In the hospital, the General Outpatient department is controlled 
Table 3. Perception of MALARIA RAPID DIAGNOSTIC TEST among respondents.

\begin{tabular}{|c|c|c|}
\hline Question & Department & Correct Response \\
\hline \multirow{4}{*}{$\begin{array}{l}\text { It is important to make a parasite-based } \\
\text { confirmation of malaria diagnosis } \\
\text { before commencing treatment }\end{array}$} & General Outpatient & $17(70.8 \%)$ \\
\hline & Internal Medicine & $16(53.3 \%)$ \\
\hline & Paediatrics & $22(68.8 \%)$ \\
\hline & OVERALL & $55(64.0 \%)$ \\
\hline \multirow{4}{*}{$\begin{array}{l}\text { MALARIA RAPID DIAGNOSTIC TEST } \\
\text { is not very useful }\end{array}$} & General Outpatient & $24(100.0 \%)$ \\
\hline & Internal Medicine & $24(80.0 \%)$ \\
\hline & Paediatrics & $30(93.8 \%)$ \\
\hline & OVERALL & $78(90.7 \%)$ \\
\hline \multirow{4}{*}{$\begin{array}{l}\text { MALARIA RAPID DIAGNOSTIC TEST } \\
\text { endangers the patient by delaying } \\
\text { initiation of treatment }\end{array}$} & General Outpatient & $24(100.0 \%)$ \\
\hline & Internal Medicine & $29(96.7 \%)$ \\
\hline & Paediatrics & $30(93.8 \%)$ \\
\hline & OVERALL & $83(96.5 \%)$ \\
\hline \multirow{4}{*}{$\begin{array}{l}\text { Presumptive diagnosis of malaria through } \\
\text { presenting symptoms is still better }\end{array}$} & General Outpatient & $23(95.8 \%)$ \\
\hline & Internal Medicine & $16(53.3 \%)$ \\
\hline & Paediatrics & $22(68.8 \%)$ \\
\hline & OVERALL & $61(70.9 \%)$ \\
\hline \multirow{4}{*}{$\begin{array}{l}\text { Malaria diagnosis is always clear } \\
\text { on listening to the patient }\end{array}$} & General Outpatient & $22(91.7 \%)$ \\
\hline & Internal Medicine & $22(73.3 \%)$ \\
\hline & Paediatrics & $22(68.8 \%)$ \\
\hline & OVERALL & $66(76.7 \%)$ \\
\hline \multirow{4}{*}{$\begin{array}{l}\text { MALARIA RAPID DIAGNOSTIC TEST } \\
\text { is hazardous }\end{array}$} & General Outpatient & $24(100.0 \%)$ \\
\hline & Internal Medicine & $27(90.0 \%)$ \\
\hline & Paediatrics & $27(84.4 \%)$ \\
\hline & OVERALL & $78(90.7 \%)$ \\
\hline \multirow{4}{*}{$\begin{array}{l}\text { MALARIA RAPID DIAGNOSTIC TEST can } \\
\text { reduce the quantity of anti-malaria drugs } \\
\text { consumed in a community }\end{array}$} & General Outpatient & $22(91.7 \%)$ \\
\hline & Internal Medicine & $22(73.3 \%)$ \\
\hline & Paediatrics & $28(87.5 \%)$ \\
\hline & OVERALL & $72(83.7 \%)$ \\
\hline \multirow{4}{*}{$\begin{array}{l}\text { MALARIA RAPID DIAGNOSTIC TEST } \\
\text { should be encouraged and promoted }\end{array}$} & General Outpatient & $24(100.0 \%)$ \\
\hline & Internal Medicine & $26(86.7 \%)$ \\
\hline & Paediatrics & $31(96.9 \%)$ \\
\hline & OVERALL & $81(94.2 \%)$ \\
\hline
\end{tabular}

Overall correct perception score for doctors in the General Outpatient department was $93.8 \%$, while that of Internal Medicine department was $75.8 \%$, and lastly those in the Paediatrics department was $72.0 \%$.

by the Community Medicine department, hence Public Health Consultants, resident doctors, and five Medical Officers consult in the Outpatient clinics. More respondents were recruited from the departments of Internal Medicine and Paediatrics probably because those departments train House Officers, hence having more doctors working in those two departments. Most of the respondents falling 
into the age range of 31 to 40 years implied that they still have a reasonable length of time to work in the hospital and manage malaria cases before their retirement. Good knowledge and correct perception of malaria rapid diagnostic test is vital in ensuring that the established guidelines are followed in malaria case management in this apex health facility.

To reduce malaria over diagnosis and misdiagnosis that occur in malaria endemic countries in Africa and Asia [11], the World Health Organization in 2010 recommended that diagnosis of malaria should be confirmed through parasite-based test; which could be Microscopy or Rapid Diagnostic Test (RDT) before commencement of treatment [10]. It is a good finding that $90.7 \%$ of the doctors working in the three key departments in the hospital that manage malaria cases were knowledgeable about this. This will enhance better malaria management practices in that teaching hospital, which is malaria apex referral centre. Respondents in all the departments exhibited impressive knowledge that parasite-based test for malaria can be done through microscopy and rapid diagnostic test; and that $\mathrm{mRDT}$ is the quick test for making a diagnosis of malaria. Approximately $90.0 \%$ of doctors in this study had this knowledge, while $78.3 \%$ of doctors that participated in a malaria diagnosis and treatment study conducted in the same study area as this one six years prior to this study, were aware of mRDT [22]. The improved knowledge on this aspect of mRDT could have resulted from the inclusion and promotion of $\mathrm{mRDT}$ in the diagnosis and treatment guidelines of World Health Organization and Federal Ministry of Health [10] [17] in 2010 and 2011 respectively. This probably made the Federal and State governments initiate and intensify activities that led to the improved knowledge observed among the doctors.

Doctors working in the General Outpatient and Paediatrics departments reported average knowledge on mRDT being specific for one or more species of malaria parasite, but those in the Internal Medicine Department reported poor knowledge of $30.0 \%$. The difference in knowledge here was significant, with Pearson's Chi-Square being 0.019. It is important that steps are taken to improve the knowledge of doctors (especially those in Internal Medicine department) on this aspect of $\mathrm{mRDT}$, so as to ensure that the correct interpretations of mRDT results are made. Knowledge level below 50\%, on mRDT detecting circulating malaria parasite antigen in the blood was found among doctors in the Internal Medicine and Paediatrics departments, while those in the General Outpatient department recorded 54.2\%, giving an overall knowledge score of $46.5 \%$. Malaria parasite antigen could persist in the blood for two weeks after the clearance of malaria parasite through chemotherapy. This could lead to false positive post-therapeutic diagnoses of malaria [23]. Doctors that are not sufficiently equipped with this knowledge could erroneously waste anti-malarial drugs on patients who had been successfully cleared of malaria parasite in the blood. Again, very poor overall knowledge of $29.1 \%$, on mRDT result being read 15 to 20 minutes after the test, was a pointer to the possibility of the doctors not correctly conducting the diagnostic test, if they were required to make use of it as a 
point-of-care test in the management of malaria.

Microscopy is still the gold standard for malaria diagnosis, since it has the ability to detect low level parasitaemia, accurate speciation, quantifiable result, and is highly sensitive; though it has the drawback of requiring properly trained Laboratory Scientist, and also stable power source [23]. Most of the respondents possessed this knowledge, though $29.1 \%$ did not know this. It is important that all medical doctors are equipped with this knowledge, so that they could still keep requesting for malaria parasite microscopy when situations are right. It is also very important for every doctor to know that mRDT is not $100 \%$ specific. Specificity is the ability of the test to detect samples that are truly negative [24]. That means that there will not be false positive results, in a test that is $100 \%$ specific. This is certainly not the case with mRDT, since among other possible situations that could give false positive results; circulating malaria antigen classically gives false positive mRDT result after the parasite has been successfully cleared from blood. This knowledge would encourage doctors to always take further steps towards validating suspicious positive mRDT results, rather than rushing to prescribe anti-malaria drugs. Though most doctors in the studied three departments had this knowledge, $20.1 \%$ of them did not. Addressing this gap will make for a more qualitative malaria case management by doctors. Malaria rapid diagnostic test was designed to overcome some of the shortcomings noted with the use of microscopy, and facilitate access to parasite-based malaria diagnosis, thus playing a key role towards the implementation of the WHO T3 initiative of Test, Treat, and Track, for malaria elimination [18]. It is therefore very suitable for use at the point-of-care by any health worker with some training. Every doctor ought to know that mRDT was designed to be performed by any health worker after undergoing some training, and not by a trained Laboratory Scientist alone. Less than $80.0 \%$ of doctors in both the General Outpatient, and Internal Medicine departments had this knowledge. Many of the doctors, especially in the Internal Medicine and General Outpatient departments, believed that there is only one type of mRDT kit. This also is a gap that needs to be addressed in order to improve on the quality of malaria case management by doctors.

This study generally revealed poorer knowledge levels of doctors working in the Internal Medicine Department, on nine out of the ten parameters used in assessing the knowledge of these doctors on mRDT; scoring below average in some cases. They only demonstrated highest knowledge on mRDT not being $100 \%$ specific. Doctors working in the Paediatrics department demonstrated highest knowledge in eight of the parameters assessed. Doctors working in the Outpatient department consistently recorded middle scores except on the issue of mRDT being $100 \%$ specific. More research work is probably required to elucidate these findings, and identify the factors that could have contributed to the findings.

Since 2010, WHO adopted and promoted the policy of confirming the diagnosis of malaria through parasite-based test where feasible, before commencing drug treatment [10], and the Nigeria National Guidelines for Diagnosis and 
Treatment of Malaria was updated to reflect this in 2011 [17], It is worrisome that as high as $36.0 \%$ of the doctors that participated in this research, do not think that it is important to make parasitological confirmation of malaria diagnosis before commencing treatment. Doctors working in the Internal Medicine department have the responsibility of treating complicated and referred malaria cases in the hospital, but they scored highest (46.7\%) in the erroneous perception that it is not important to confirm malaria infection through parasite-based test before treating. Again, reasonable number of doctors (20.0\%) working in the Internal Medicine department did not perceive mRDT as being useful, while all the doctors working in General Outpatient, and 93.8\% of those in Paediatrics departments did not share this wrong perception. mRDT has been shown to be effective even in low transmission areas [25]. Some studies in Africa revealed that using mRDT enhanced correct treatment of malaria more than microscopy [26] [27]. It is important that these wrong perceptions among doctors about mRDT be addressed so that doctors effectively play leading roles aimed at using mRDT as an important tool for implementing the WHO malaria Test, Treat and Trackinitiative.

The use of presumptive diagnosis in the management of malaria commonly leads to diagnostic inaccuracies and over-diagnosis of malaria [28] [29]. This could endanger patients that have more deadly conditions such as Lassa fever or Yellow fever, by being erroneously treated for malaria while delaying the initiation of correct treatment for some of these potentially fatal diseases; whose prognoses is positively affected by early initiation of treatment. The Turn-Around-Time (TAT) for malaria diagnosis using mRDT is a lot less than the two hours recommended by WHO, since the result is read 15 to 20 minutes after adding the buffer. mRDT therefore does not endanger the patient by delaying the initiation of treatment. It is an encouraging finding that $96.5 \%$ of respondents in this study did not have this wrong perception. The finding that as many as $29.1 \%$ of doctors that participated in this study perceived presumptive diagnosis of malaria through presenting symptoms, as being preferable is somewhat disappointing. The implication is that as high as that percentage of doctors in those studied three departments would keep making diagnosis of malaria presumptively, even when mRDT is available and accessible. This gap needs to be addressed. The perception by up to $23.3 \%$ of the doctors in this study, that malaria diagnosis is always clear on listening to the patients, also ought to be addressed if the benefits derivable from the implementation of the T3 initiative are to be maximally reaped.

Though mRDT ought not to be exclusively done by qualified Laboratory Scientists, the procedure should be carried out by health care providers who have been trained on how to conduct this test [9]. An aspect of the training usually deals with Universal safety precautions when dealing with blood in health facility environment. mRDT being conducted only by trained staff, ensures that no hazards are associated with the procedure. In this study, all the 
doctors in the General Outpatient department, and $90 \%$ of those in the Internal Medicine department do not perceive mRDT as being hazardous. The situation is slightly less impressive in the Paediatrics department, where $84.4 \%$ of their doctors do not see mRDT as being hazardous. In the assessment of the knowledge of respondents on some aspects of mRDT, doctors working in the Paediatrics department demonstrated superior knowledge in most of the aspects assessed. It is then a bit curious that up to $15.6 \%$ of them should erroneously perceive $\mathrm{mRDT}$ as being hazardous. Some studies, such as the one conducted in Malawi [30], found that prescribing anti-malaria drugs to only patients that tested positive after parasitological examination of the blood reduced the total number of anti-malaria medicine prescriptions; and by extension the quantity of anti-malaria drugs consumed in a community. Furthermore, introduction of mRDTs in places where malaria diagnosis was usually through presumptive method, demonstrated significant reduction in over prescription of anti-malaria drugs [31]. One would have thought that all medically qualified personnel ought to have been conversant with this apparently deducible finding. In this study, averagely up to $16.3 \%$ do not perceive $\mathrm{mRDT}$ as being able to reduce the quantity of anti-malaria consumed in a community. WHO recommended mRDT as a useful tool in achieving the objectives of the T3 Initiative; hence it is important that all doctors perceive mRDT as malaria management tool that should be encouraged and promoted. This is not the finding in this study.

Contrary to the finding on the assessment of knowledge aspect of this study, where doctors in the Paediatrics department exhibited superior knowledge on the parameters studied; those that work in the general outpatient department scored highest on the correct perception of the parameters studied. Qualitative study to investigate the factors that influence the knowledge and perception of these doctors on $\mathrm{mRDT}$ promises to be revealing.

\section{Conclusions}

Doctors in the Paediatrics department had overall better knowledge on mRDT, followed by those in the General Outpatient department, while the knowledge level for doctors in the Internal Medicine department was lowest. Overall, doctors in the General Outpatient department recorded the highest score on correct perception, while those in Paediatrics department had the least score on perception. It is curious that doctors in the Paediatrics department who were reported highest knowledge level on mRDT, should have the highest erroneous perception of mRDT. Investigating the factors that could have possibly led to this could be revealing.

Malaria Rapid diagnostic Test is designed to reduce the turn-around-time for malaria diagnosis, and make it more accessible for confirming suspected cases of malaria. It is also designed not to require specialized training for health workers who perform the test. Since it has been shown to be reliable, all health workers, particularly medical doctors ought to be equipped with correct information 
about this diagnostic tool for malaria. This could be done through properly planned training and re-training programme for health workers. Doctors in the tertiary health institutions which are the apex referral facilities for the management of malaria need to be convinced about the vital role $\mathrm{mRDT}$ is designed to play in the malaria elimination efforts. Training and re-training of health workers shall greatly enhance mRDT use in implementing the WHO T3 Initiative, and ultimately eliminating malaria.

\section{References}

[1] Park, K. (2013) Textbook of Preventive and Social Medicine, 22nd Edition. M/s Banarsidas Bhanot Publishers, Jabalpur.

[2] World Health Organization (2015) Guidelines for the Treatment of Malaria. 3rd Edition, WHO, Geneva.

[3] Olise, P. (2011) Primary Health Care for Sustainable Development. 2nd Edition, Ozege Publications, Abuja.

[4] World Health Organization (2016) World Malaria Report. WHO, Geneva.

[5] World Health Organization (2014) World Malaria Report. WHO, Geneva.

[6] National Malaria Elimination Programme, Nigeria (2014) National Malaria Strategic Plan 2014-2020. Federal Ministry of Health, Abuja.

[7] World Health Organization (2013) World Malaria Report. WHO, Geneva.

[8] National Malaria Control Programme, Nigeria (2006) National Malaria Control Programme 5 Years Strategic Plan 2006-2014. Federal Ministry of Health, Abuja.

[9] National Malaria and Vector Control Division, Nigeria (2011) National Policy on Malaria Diagnosis and Treatment. Federal Ministry of Health, Abuja.

[10] World Health Organization (2010) Guidelines for the Treatment of Malaria. 2nd Edition, WHO, Geneva.

[11] Whitty, C., Chandler, C., Ansah, E., Leslie, T. and Staedike, S. (2008) Deployment of ACT Antimalarials for Treatment of Malaria: Challenges and Opportunities. Malaria Journal, 7, 57. https://doi.org/10.1186/1475-2875-7-S1-S7

[12] Murray, C.K., Grasser, R.A., Magill, A.J. and Miller, R.S. (2008) Update on Rapid Diagnostic Testing for Malaria. Clinical Microbiology Reviews, 21, 97-110. https://doi.org/10.1128/CMR.00035-07

[13] World Health Organization (2013) Seasonal Malaria Chemoprevention with Sulfadoxine-Pyrimethamine plus Amodiaquine in Children: A Field Guide. WHO, Geneva.

[14] Chandler, C., Jones, C., Boniface, G., Juma, K., Rayburn, H. and Whitty, C.J. (2008) Guidelines and Midlines: Why Do Clinical Staff Over-Diagnose Malaria in Tanzania? A Qualitative Study. Malaria Journal, 7, 53. https://doi.org/10.1186/1475-2875-7-53

[15] World Health Organization (2012) T3, Test, Treat, Track, Brochure. WHO, Geneva.

[16] Uzochukwu, B.S.C., Obikeze, E.N., Onwujekwe, O.E., Onoka, C.A. and Grifiths, U.K. (2009) Cost-Effective Analysis of Rapid Diagnostic Test, Microscopy, and Syndromic Approach in the Diagnosis of Malaria in Nigeria: Implications for Scaling-Up Deploiyment of ACT. Malaria Journal, 8, 265. https://doi.org/10.1186/1475-2875-8-265

[17] Federal Ministry of Health (2011) National Guidelines for Diagnosis and Treatment 
of Malaria. FMOH, Abuja.

[18] World Health Organization (2012) Test, Treat, Track: Scaling up Diagnostic Testing, Treatment and Surveillance for Malaria. WHO, Geneva.

[19] Ansah, E.K., Narh-Bana, S., Epokor, M., Akanpigbiam, S., Quartey, A.A., Gyapong, J. and Whitty, C.J. (2010) Rapid Testing for Malaria in Settings Where Microscopy Is Available and Peripheral Clinics Where Only Presumptive Treatment Is Available: A Randomized Controlled Trial in Ghana. BMJ, 340, c930. https://doi.org/10.1136/bmj.c930

[20] Oguonu, T. and Okafor, H.U. (2007) Comparison of Clinical, Microscopic and Rapid Diagnostic Test Methods in the Diagnosis of Plasmodium falciparum Malaria in Enugu, Nigeria. Nigerian Postgraduate Medical Journal, 14, 285-289.

[21] Uzochukwu, B.S., Onwujekwe, E., Ezuma, N.N., Ezeoke, O.P., Ajuba, M.O. and Sibendu, F.T. (2011) Improving Rational Treatment of Malaria: Perceptions and Influence of RDTs on Prescribing Behaviour of Health Workers in Southeast Nigeria. PLOS ONE, 6, e14627. https://doi.org/10.1371/journal.pone.0014627

[22] Uzochukwu, B.S.C., Chiegboka, L.O., Enwereuzo, C., Nwosu, U., Okafor, D., Onwujekwe, O.E., Uguru, N.P., Sbeudu, F.T. and Ezeoke, O.P. (2010) Examining Appropriate Diagnosis and Treatment of Malaria: Availability and Use of Rapid Diagnostic Tests and Athemisinin-Based Combination Therapy in Public and Private Health Facilities in Southeast Nigeria. BMC Public Health, 10, 486.

https://doi.org/10.1186/1471-2458-10-486

[23] Berger, B.J. (2005) Rapid Diagnostic Test for Malaria: A Review. Defense Research and Development, Suffield-Canada.

[24] Lucas, A.O. and Gilles, H.M. (2003) Short Textbook of Public Health Medicine for the Tropics. International Students' Edition, ARNOLD Publishers, London.

[25] Leslie, T., Mikhail, A., Mayan, I., Cundill, B., Anwar, M., Bakhtash, S.H., Mohammed, N., Rahman, H., Zekria, R., Whitty, C.J.M. and Rowland, M. (2014) Rapid Diagnostic Tests to Improve Treatment of Malaria and Other Febrile Illnesses: Patient Randomized Effectiveness Trial in Primary Care Clinics Afghanistan. BMJ, 348, g3730. https://doi.org/10.1136/bmj.g3730

[26] Harchut, K., Standly, C., Dobson, A., Klaassen, B., Rambaud-Althaus, C., Althaus, F. and Nowak, K. (2013) Over-Diagnosis of Malaria by Microscopy in the Kilombero Valley, Southern Tanzania: An Evaluation of the Utility and Cost Effectiveness of Rapid Diagnostic Tests. Malaria Journal, 12, 159. https://doi.org/10.1186/1475-2875-12-159

[27] Ansah, E.K., Epokor, M., Whitty, C.M., Yeung, S. and Hansen, K.S. (2013) Cost-Effectiveness Analysis of Introducing RDTs for Malaria Diagnosis as Compared to Microscopy and Presumptive Diagnosis in Central and Peripheral Public Health Facilities in Ghana. The American Journal of Tropical Medicine and Hygiene, 89, 724-736. https://doi.org/10.4269/ajtmh.13-0033

[28] Reyburn, H., Mbatia, R., Drakely, C., Carneiro, L., Mwakasungula, E., Mwerinde, O., Saganda, K., Shao, J., Kitua, A., Olomi, R., Greenwood, B.M. and Whitty, C.J.M. (2004) Over-Diagnosis of Malaria in Patients with Severe Febrile Illness in Tanzania: A Prospective Study. BMJ, 329, 1212.

https://doi.org/10.1136/bmj.38251.658229.55

[29] Font, F., Alonzo-Gonzalez, M., Nathan, R., Kimario, J., Lwilla, F., Ascaso, C., Tanner, M., Menendez, C. and Alozo, P.L. (2001) Diagnostic Accuracy and Case Management of Clinical Malaria in the Primary Health Services of a Rural Area in Southeastern Tanzania. Tropical Medicine \& International Health, 6, 423-428. 
https://doi.org/10.1046/j.1365-3156.2001.00727.x

[30] Chitaka, R., Khare, A.K. and Brickling, C. (1998) Prescribing Policy for Anti-Malarias. Africa Health, 20, 2-5.

[31] Bastiaens, G.J.H., Bousema, T. and Leslie, T. (2014) Scale-Up of Malaria Rapid Diagnostic Tests and Artemisinin-Bases Combination Therapy: Challenges and Perspectives in Sub-Saharan Africa. PLOS Medicine, 11, e1001590.

https://doi.org/10.1371/journal.pmed.1001590 